\title{
Sulfenylphosphinoferrocenes: Novel planar chiral ligands in enantioselective catalysis*
}

\author{
Silvia Cabrera, Olga García Mancheño, Ramón Gómez Arrayás, \\ Inés Alonso, Pablo Mauleón, and Juan C. Carreteroł
}

\author{
Departamento de Química Orgánica, Facultad de Ciencias, Universidad Autónoma \\ de Madrid, 28049 Madrid, Spain
}

\begin{abstract}
Structurally well-defined transition-metal complexes of 1-phosphino-2-sulfenylferrocene (Fesulphos ligands) act as highly efficient catalysts in a variety of mechanistically different transformations. Excellent enantioselectivities were achieved in Pd-catalyzed allylic substitutions, desymmetrization of meso-heterobicyclic alkenes by Pd-catalyzed addition of dialkylzinc reagents, Pd-catalyzed Diels-Alder reaction of cyclopentadiene with $N$-acryloyl oxazolidinones, and in Cu-catalyzed formal aza-Diels-Alder reaction of Danishefsky diene to $N$-sulfonyl aldimines.
\end{abstract}

Keywords: sulfenylphosphinoferrocenes; Fesulphos; enantioselective; Pd-catalyzed; allylic substitutions; desymmetrization; Danishefsky diene; $N$-sulfonyl aldimines; Cu-catalyzed.

\section{INTRODUCTION}

Two main structural concepts have proved to be greatly successful in the design of chiral ligands for asymmetric catalysis: The reduction of the possible diastereomeric transition states by using bidentate C2-symmetrical P/P, N/N, or O/O chiral ligands (e.g., BINAP, bisoxazolines, salen, or BINOL-based ligands) and the use of mixed bidentated ligands equipped with strong and weak donor heteroatom pairs [1]. This second strategy takes advantage of the different electronic properties associated with each heteroatom-metal bond (e.g., the trans influence) which, playing in combination with appropriate steric effects around the metal-coordinating heteroatoms, can create an asymmetric environment capable of inducing high levels of enantiocontrol. Some bidentate $\mathrm{P} / \mathrm{N}$ chiral ligands such as phosphine-oxazoline systems and QUINAP constitute excellent examples of this strategy [2].

Unlike mixed P/N ligands, thioether-based bidentate ligands have received much less attention. However, structures combining phosphine and tioether moieties are very appealing coordinating systems since, in addition to the strong electronic differentiation imposed by the phosphorus and sulfur heteroatoms, the sulfur atom becomes stereogenic upon coordination with the metal, which enforces a unique asymmetric environment very close to the reactive metal center. In this field, we described in 2002 a highly modulable family of P/S ligands having planar chirality only, the 1-phosphino-2-sulfenylferrocenes (Fesulphos ligands), which are readily available in few steps and gram quantities from ferrocene [3a]. Interestingly, a very bulky substitution at sulfur (e.g., tert-butyl group) provides a single epimer at sulfur upon P,S coordination to the transition metal, that one orienting the tert-butyl group at

\footnotetext{
*Pure Appl. Chem. 78, 197-523. An issue of reviews and research papers based on lectures presented at the $13^{\text {th }}$ IUPAC International Symposium on Organometallic Chemistry Directed Towards Organic Synthesis (OMCOS-13), Geneva, Switzerland, 17-21 July 2005.

¥Corresponding author: Fax: +34 914973966; E-mail: juancarlos.carretero@uam.es
} 
sulfur in anti arrangement with regard to the ferrocene unit. We briefly summarize herein that by finetuning the steric and electronic properties at phosphorus, these well-defined P,S metal complexes behave as very efficient catalysts in enantioselective Pd-catalyzed reactions such as allylic substitution [3a] and ring-opening addition of dialkylzinc reagents to heterobicyclic alkenes [4], as well as highly selective chiral Lewis acids in classical $\mathrm{C}-\mathrm{C}$ and $\mathrm{C}-\mathrm{X}$ bond-forming reactions, such as Diels-Alder reactions [5] and aza-Diels-Alder reactions [6].

\section{SYNTHESIS OF FESULPHOS LIGANDS}

Fesulphos ligands are readily prepared according to the following three-step sequence: sulfinylation of ferrocene, ortho-lithiation/phosphination, and sulfoxide to sulfide reduction (Scheme 1). The asymmetric sulfinylation of ferrocenyllithium with $(R)$-tert-butyl tert-butanethiosulfinate takes place with complete inversion of configuration at sulfur, providing the tert-butylsulfinyl ferrocene $(R)-\mathbf{1}$. According to the pioneering work of Kagan et al. [7], the ortho-lithiation of sulfinylferrocenes occurs with complete diastereocontrol at $\mathrm{C} 2$. Subsequent quenching of the resulting ortho-lithiated species with a chlorophosphine leads to the corresponding 1-tert-butylsulfinyl-2-phosphinoferrocene $(R, R)$-2 in excellent yield. The final reduction of the sulfoxide with $\mathrm{HSiCl}_{3} / \mathrm{Et}_{3} \mathrm{~N}$ gives the enantiopure Fesulphos ligands $(R)-\mathbf{3 a}-\mathbf{g}$. This modular synthetic approach has been equally applied to the construction of ligands with other substitution at sulfur or different organometallic platform. For instance, the $p$-tolylsulfenyl Fesulphos ligand $\mathbf{3 h}$ was prepared starting from $(S)$-p-tolylsulfinylferrocene, while the nonferrocene ligand $3 \mathbf{i}$ was obtained using a sulfinylated cyclopentadienyl $\eta^{4}$-cyclobutadiene cobalt complex instead of the sulfinyl ferrocene unit.

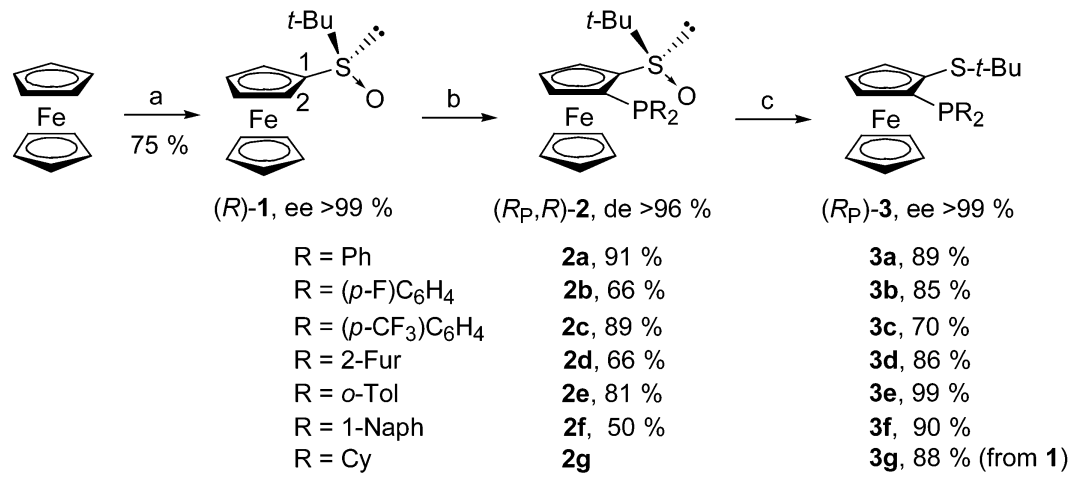

(a) $t$-BuLi, THF-pentane, $-78^{\circ} \mathrm{C}$; $t$-Bu-S(O)-S-t-Bu; (b) $t$-BuLi, THF, $-78^{\circ} \mathrm{C} ; \mathrm{R}_{2} \mathrm{PCl}$; (c) $\mathrm{HSiCl}_{3}, \mathrm{Et}_{3} \mathrm{~N}$, toluene, $110^{\circ} \mathrm{C}$

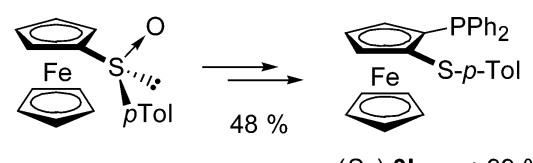

$\left(S_{\mathrm{P}}\right)-\mathbf{3 h}$, ee $>99 \%$
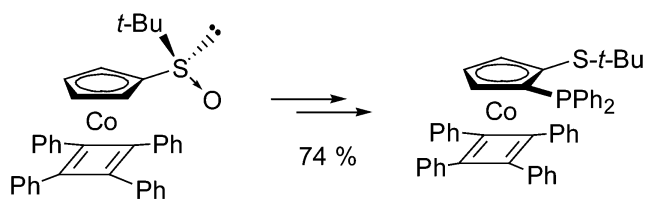

$\left(R_{\mathrm{P}}\right)-\mathbf{3 i}$, ee $>99 \%$

Scheme 1 Synthesis of Fesulphos ligands. 


\section{FESULPHOS LIGANDS IN PALLADIUM-CATALYZED REACTIONS}

\section{Allylic substitution}

As first reaction, these sterically and electronically varied P,S-ligands were evaluated as chiral catalysts in the standard Pd-catalyzed allylic substitution of dimethyl malonate with 1,3-diphenyl-2-propenyl acetate (Scheme 2). With the exception of the $p$-tolylsulfenyl ligand $\mathbf{3 h}$, high enantioselectivities were obtained with all the tert-butylsulfenyl ligands, being the highest asymmetric inductions achieved with the electronically poor phosphines $\mathbf{3 b}$ (97\% ee) and 3c (96\% ee), and the cobalt complex 3i (98\% ee). Even higher enantioselectivities (up to $99.5 \%$ ee) were obtained in the reaction with nitrogen nucleophiles such as benzylamine or potassium ftalimide.

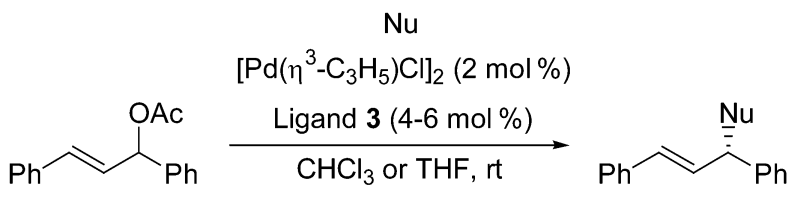

\begin{tabular}{|c|c|c|c|}
\hline $\mathrm{Nu}$ & Ligand & Yield (\%) & $\mathrm{Ee}(\%)$ \\
\hline \multirow[t]{9}{*}{$\left(\mathrm{CO}_{2} \mathrm{Me}\right)_{2} \mathrm{CH}_{2}$} & $3 a$ & 87 & $96^{\mathrm{a}}$ \\
\hline & $3 b$ & 91 & $97^{\mathrm{a}}$ \\
\hline & $3 c$ & 98 & $96^{\mathrm{a}}$ \\
\hline & $3 d$ & 60 & 90 \\
\hline & $3 e$ & 97 & 73 \\
\hline & $3 f$ & 95 & 71 \\
\hline & $3 g$ & 96 & 84 \\
\hline & $3 h$ & 92 & 40 \\
\hline & $3 \mathbf{i}$ & 99 & 98 \\
\hline \multirow[t]{2}{*}{$\mathrm{BnNH}_{2}$} & $3 b$ & 89 & 98 \\
\hline & $3 f$ & 93 & 99.5 \\
\hline KPhth & $3 \mathbf{i}$ & 80 & 99 \\
\hline
\end{tabular}

Scheme 2 Fesulphos ligands in Pd-catalyzed allylic substitutions on 1,3-diphenyl-2-propenyl acetate.

To gain mechanistic insight into the origin of the asymmetric efficiency of Fesulphos ligands, we isolated the presumed cationic $\pi$-allyl Pd complex intermediate of two of the best ligands (ferrocene $\mathbf{3 b}$ and cobalt complex 3i) by stoichiometric reaction with (trans-1,3-diphenylpropenyl)palladium dichloride dimer in the absence of any nucleophile. These complexes were fully studied by NMR, showing that the W-type diastereomer was both the major isomer in solution (3:1 isomer ratio) and the most reactive, as evidenced by the very high chemical shift of the carbon trans to phosphorus on the $\pi$-allyl termini. Thus, the selective attack of the nucleophile trans to phosphorus on this $\pi$-allylpalladium complex could readily explain the formation of the observed enantiomer (Scheme 3). The X-ray diffraction analysis of the allyl-Pd complex of ligand $\mathbf{3 i}$ confirmed the W-type stereochemistry and the much greater trans influence of phosphorus compared to sulfur, as evidenced by the longer length of the $\mathrm{Pd}-\mathrm{C}$ trans to phosphorus $(2.259 \AA)$ than trans to sulfur $(2.183 \AA)$. 


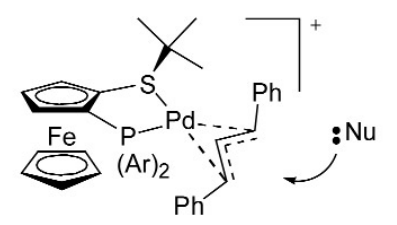

$\overbrace{\mathrm{Ph}}^{\downarrow} \overbrace{\mathrm{i} u}^{\mathrm{Nu}}$

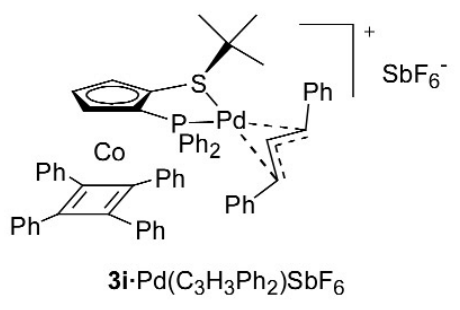

Crystal structure of $\mathbf{3 i} \cdot \mathrm{Pd}\left(\mathrm{C}_{3} \mathrm{H}_{3} \mathrm{Ph}_{2}\right) \mathrm{SbF}_{6}$

Scheme $3 \pi$-Allyl Pd complexes of Fesulphos ligands.

\section{Alkylative ring opening of oxabicyclic alkenes with organozinc reagents}

The Pd-catalyzed enantioselective ring opening of meso oxabicyclic alkenes with dialkylzinc reagents is a very interesting $\mathrm{C}-\mathrm{C}$ bond-forming reaction recently reported by Lautens et al. [8]. High enantioselectivities have been described using priviledged P,P and P,N chiral ligands, such as Tol-BINAP and phosphinooxazolines. Inspired by mechanistic studies suggesting the participation of cationic alkyl palladium species $\left[\mathrm{L}_{2} \mathrm{PdR}\right]^{+}$as key active catalytic species [9], we envisaged that the cationic methyl-palladium complexes of Fesulphos $[(\mathbf{3}) \mathrm{PdMe}]^{+}$could function as very active catalysts in this reaction. Scheme 4 shows the preparation of such cationic structures. Treatment of $\mathbf{3}$ with $\mathrm{PdCl}_{2}\left(\mathrm{CH}_{3} \mathrm{CN}\right)_{2}$ afforded in very high yield the corresponding complexes $\left[3 \cdot \mathrm{PdCl}_{2}\right]$ as single epimers at sulfur. The transmetallation reaction of these complexes with $\mathrm{Me}_{2} \mathrm{Zn}$ was completely stereoselective, affording a single complex $[3 \cdot \mathrm{Pd}(\mathrm{Cl})(\mathrm{Me})]$ in $70-95 \%$ yield. The final dissociation of the chloride ligand was achieved by treatment with a silver salt $\left(\mathrm{AgPF}_{6}\right.$ or $\left.\mathrm{AgSbF}_{6}\right)$ or using the Brookhart's reagent $\left[\mathrm{NaB}\left(\mathrm{Ar}^{\mathrm{F}}\right)_{4}, \mathrm{Ar}^{\mathrm{F}}=\right.$ 3,5-bis(trifluoromethyl)phenyl], in benzonitrile as cosolvent, the corresponding cationic complexes being obtained as robust air-stable compounds. The cis arrangement of the methyl group and the phosphine was unequivocally established by $\mathrm{X}$-ray crystal diffraction analysis of the neutral complex $[(\mathbf{3 a}) \mathrm{Pd}(\mathrm{Cl})(\mathrm{Me})]$ and the cationic benzonitrile complex $[\mathbf{3 a} \cdot \mathrm{Pd}(\mathrm{Me})(\mathrm{PhCN})]^{+}\left[\mathrm{B}\left(\mathrm{Ar}^{\mathrm{F}}{ }_{4}\right)\right]^{-}$.

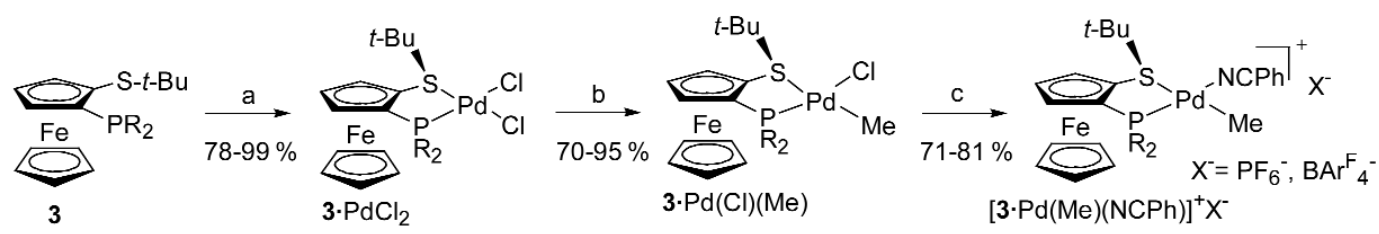

a) $\mathrm{PdCl}_{2}\left(\mathrm{CH}_{3} \mathrm{CN}\right)_{2}, \mathrm{CH}_{2} \mathrm{Cl}_{2}, \mathrm{rt}$; b) $\mathrm{Me}_{2} \mathrm{Zn}$ (1.5 equiv), $\mathrm{CH}_{2} \mathrm{Cl}_{2}$, rt; c) $\mathrm{AgPF}_{6}$ or $\mathrm{NaBAr}_{4}, \mathrm{PhCN}_{2} \mathrm{CH}_{2} \mathrm{Cl}_{2}$, rt.

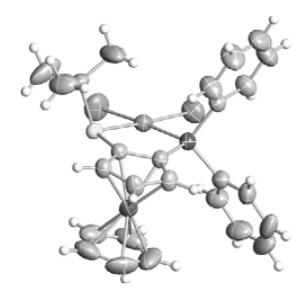

Crystal structure of $\mathbf{3 a} \cdot \mathrm{PdCl}_{2}$

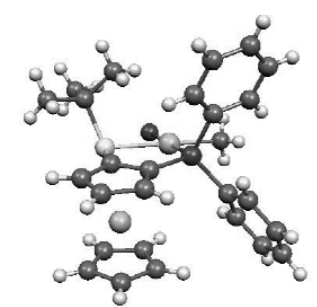

Crystal structure of $3 a \cdot P d(C l)(\mathrm{Me})$

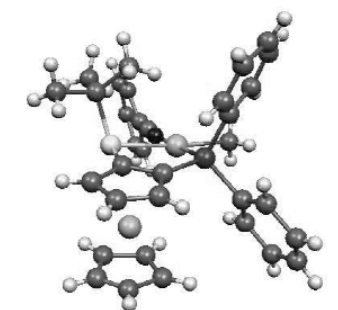

Crystal structure of $3 a \cdot P d(\mathrm{Me})(\mathrm{NCPh})$

Scheme 4 Synthesis and crystal structures of Fesulphos Pd complexes. 
Studying as model reaction the ring opening of oxabenzonorbornadiene with $\mathrm{Me}_{2} \mathrm{Zn}$, we were pleased to confirm that the cationic complex $[\mathbf{3 a} \cdot \operatorname{Pd}(\mathrm{Me})]\left[\mathrm{B}\left(\mathrm{Ar}_{4}{ }_{4}\right)\right]$ was much more reactive than any of its neutral precursors. For instance, in the presence of $5 \mathrm{~mol} \%$ of catalyst the reaction in the presence of $\mathbf{3 a}+\mathrm{PdCl}_{2}\left(\mathrm{CH}_{3} \mathrm{CN}\right)_{2},\left[\mathbf{3 a} \cdot \mathrm{PdCl}_{2}\right]$, or $[\mathbf{1 a} \cdot \mathrm{Pd}(\mathrm{Cl})(\mathrm{Me})]$ required 24-48 $\mathrm{h}$ for complete conversion at $\mathrm{rt}$, while in the presence of $[\mathbf{3 a} \cdot \mathrm{Pd}(\mathrm{Me})]\left[\mathrm{B}\left(\mathrm{Ar}^{\mathrm{F}}{ }_{4}\right)\right]$ the reaction was over in less than $10 \mathrm{~min}$, providing the opening product $(R, R)-\mathbf{4}$ in $78 \%$ ee (Scheme 5). This strong acceleration effect allowed a dramatic decrease of the catalyst loading to $0.2-0.5 \mathrm{~mol} \%$. To fine-tune the enantioselectivity of the process, we next studied the effect of the substitution at phosphorus (cationic complexes of ligands $\mathbf{3 b}-\mathbf{e})$, the complex of the electronically rich dicyclohexyl phosphane $\mathbf{3 g}$ providing by far the best results. For instance, the combination of $[3 \mathrm{~g} \cdot \mathrm{Pd}(\mathrm{Cl})(\mathrm{Me})]+\mathrm{NaB}\left(\mathrm{Ar}^{\mathrm{F}}\right)_{4}$ proved to be so effective that catalyst loading as low as $0.2 \mathrm{~mol} \%$ was sufficient to reach quantitative conversion within $5 \mathrm{~h}$ at $-25^{\circ} \mathrm{C}$, which led to alcohol $\mathbf{4 a}$ in $88 \%$ yield with $97 \%$ ee.
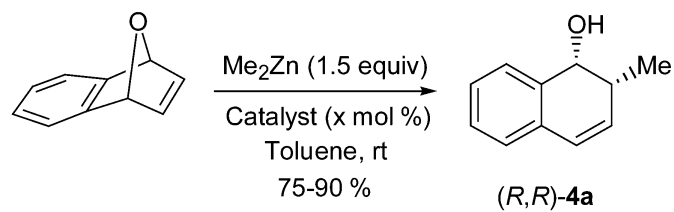

\begin{tabular}{lll}
\hline Catalyst $(x \mathrm{~mol} \%)$ & time & $\mathrm{Ee}(\%)$ \\
\hline$\left[3 \mathbf{a}+\mathrm{PdCl}_{2}\left(\mathrm{CH}_{3} \mathrm{CN}\right)_{2}\right](5.0)$ & $24 \mathrm{~h}$ & 88 \\
{$\left[3 \mathrm{a} \cdot \mathrm{PdCl}{ }_{2}\right](5.0)$} & $24 \mathrm{~h}$ & 81 \\
{$[3 \mathrm{a} \cdot \mathrm{Pd}(\mathrm{Cl})(\mathrm{Me})](5.0)$} & $48 \mathrm{~h}$ & 85 \\
{$[3 \mathbf{a} \cdot \mathrm{Pd}(\mathrm{Cl})(\mathrm{Me})]+\mathrm{NaBAr}{ }_{4}(5.0)$} & $<10 \mathrm{~min}$ & 78 \\
{$[3 \mathbf{a} \cdot \mathrm{Pd}(\mathrm{Cl})(\mathrm{Me})]+\mathrm{NaBAr}_{4}(0.5)$} & $30 \mathrm{~min}$ & 78 \\
{$[3 \mathbf{g} \cdot \mathrm{Pd}(\mathrm{Cl})(\mathrm{Me})]+\mathrm{NaBAr}_{4}(1.0)$} & $60 \mathrm{~min}^{\mathrm{a}}$ & 97 \\
{$[3 \mathbf{g} \cdot \mathrm{Pd}(\mathrm{Cl})(\mathrm{Me})]+\mathrm{NaBAr}_{4}(0.2)$} & $5 \mathrm{~h}^{\mathrm{a}}$ & 97 \\
\hline
\end{tabular}

${ }^{\text {a }}$ Reaction performed at $-20^{\circ} \mathrm{C}$

Scheme 5 Ring opening of 7-oxabenzonorbornadiene with $\mathrm{Me}_{2} \mathrm{Zn}$ catalyzed by Pd complexes of ligands 3 .

Figure 1 highlights the scope of the process catalyzed by the optimal catalyst $[\mathbf{3 g} \cdot \operatorname{Pd}(\mathrm{Me})]$ $\left[\mathrm{B}\left(\mathrm{Ar}_{4}{ }_{4}\right)\right]$. Complete conversions within 10-30 min, good chemical yields (61-98\%) and excellent enantioselectivities (94-99\% ee) were obtained in the ring opening of a variety of substituted meso oxabenzonorbornadienes with $\mathrm{Me}_{2} \mathrm{Zn}, \mathrm{Et}_{2} \mathrm{Zn}$, and $\mathrm{Bu}_{2} \mathrm{Zn}$ using $0.5 \mathrm{~mol} \%$ catalyst loading.

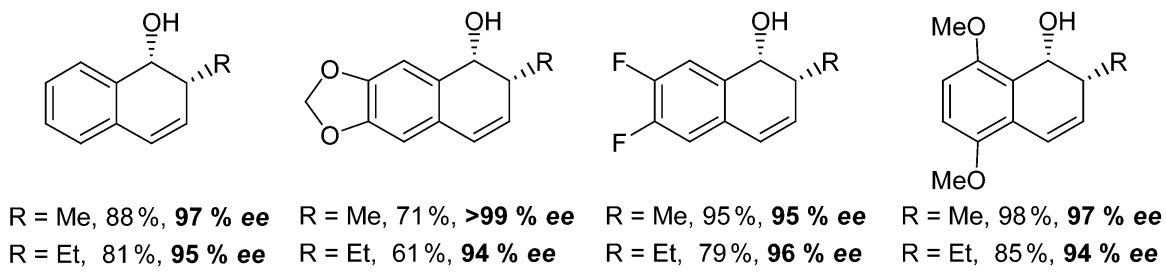

Fig. 1 Scope of the ring-opening reactions catalyzed by $[3 \mathrm{gg} \cdot \mathrm{PdMe}]^{+}$.

As shown in Scheme 6, these Fesulphos cationic methyl-palladium complexes also allow the alkylative ring opening of much less reactive substrates, such as nonaromatic meso [2.2.1]-oxabicyclic alkenes and azabenzonorbornadiene derivatives. In both cases, extremely high enantioselectivities were achieved in the reaction with $\mathrm{Me}_{2} \mathrm{Zn}(97->99 \%$ ee). 

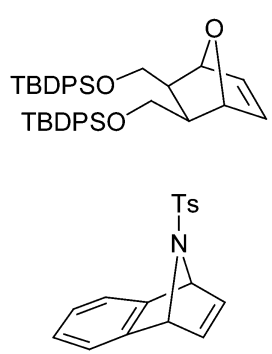

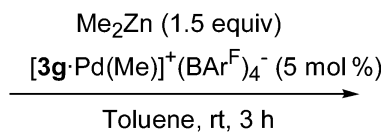

$\mathrm{Me}_{2} \mathrm{Zn}$ (1.5 equiv)

$\underset{\text { DCE-Tol (1:2), rt, } 30 \mathrm{~min}}{\stackrel{[3 \mathbf{a} \cdot \mathrm{Pd}(\mathrm{Me})]^{+} \mathrm{PF}_{6}^{-}(5 \mathrm{~mol} \%)}{\longrightarrow}}$<smiles>CC(C)COC[C@@H]1C=C[C@H](C)[C@H](O)[C@H]1COCC(C)C</smiles>

$61 \%, 97 \%$ ee

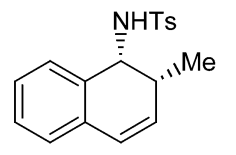

$73 \%,>99 \%$ ee

Scheme 6 Ring opening of less reactive meso substrates.

The X-ray structure of the cationic complex $[(\mathbf{3 a}) \mathrm{PdMe}]^{+}$(Scheme 4) suggests that the high asymmetric induction displayed by these catalysts could rely on the strong trans effect of the phosphane moiety that acts in combination with the sterically demanding environment imposed by the stereogenic sulfur atom directly bonded to the palladium. The presumed key $\pi$-alkene coordinated complex involved in the catalytic cycle is shown in Scheme 7.

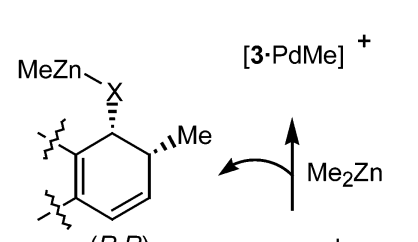

$(R, R)$

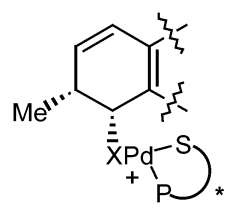

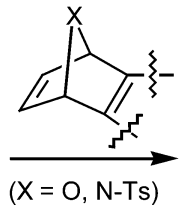

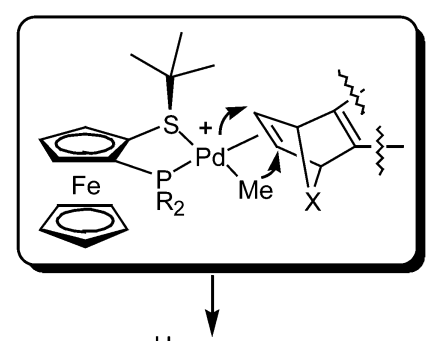

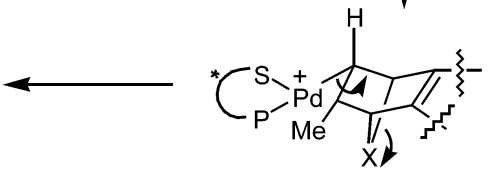

Scheme 7 Mechanistic proposal.

\section{METAL COMPLEXES OF FESULPHOS AS CHIRAL LEWIS ACIDS}

\section{Diels-Alder reaction of cyclopentadiene with $\mathbf{N}$-acryloyl oxazolidinone}

In the screening of new chiral Lewis acids for asymmetric Diels-Alder reactions, the cycloaddition of cyclopentadiene with acryloyl 1,3-oxazolidin-2-one is one of the standard test processes. After surveying several metal complexes of Fesulphos ligands, the Pd complexes were found to afford the highest enantioselectivities, especially those of ligands with a bulky substitution at phosphorus. For instance, the reaction in $\mathrm{CH}_{2} \mathrm{Cl}_{2}$ at $-78{ }^{\circ} \mathrm{C}$ catalyzed by the combination $3 \mathrm{e} \cdot \mathrm{PdCl}_{2}+\mathrm{AgBF}_{4}$ gave the endo adduct $(R)-5$ in $90 \%$ yield and $95 \%$ ee (Scheme 8 ). Interestingly, the $\mathrm{Cu}(\mathrm{I})$ complex of the same ligand $[3 \mathrm{e} \cdot \mathrm{CuCl}]_{2}$ led to the opposite enantiomer $(S)-5$ in $54 \%$ ee. This opposite enantiodiscrimination displayed by $\mathrm{Pd}$ and $\mathrm{Cu}$ Fesulphos complexes could be ascribed to the different geometry at the metal center (square planar in the $\mathrm{Pd}$ complex $\mathbf{3} \cdot \mathrm{PdCl}_{2}$ and tetrahedral-like in the complex $[\mathbf{3 a} \cdot \mathrm{CuCl}]_{2}$ ). 


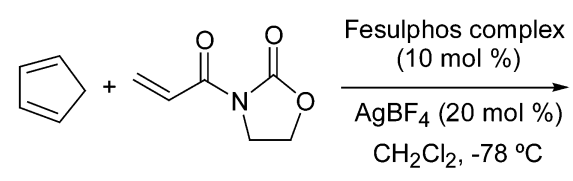

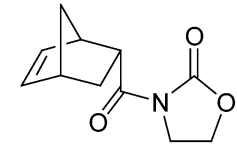

$(R)-5$ endo

\begin{tabular}{lccc}
\hline Complex & Yield & endo/exo & Ee $(\%)$ \\
\hline 3a $\cdot \mathrm{PdCl}_{2}$ & 69 & $95: 5$ & $67(R)$ \\
3f $\cdot \mathrm{PdCl}_{2}$ & 35 & $96: 4$ & $80(R)$ \\
3e $\cdot \mathrm{PdCl}_{2}$ & 90 & $98: 2$ & $95(R)$ \\
{$[\text { 3e } \cdot \mathrm{CuBr}]_{2}$} & 87 & $99: 1$ & $54(S)$ \\
\hline
\end{tabular}

Scheme 8 Metal complexes of Fesulphos in the reaction of cyclopentadiene with $N$-acryloyl oxazolidinone.

\section{aza-Diels-Alder reaction of Danishefsky diene with $\mathbf{N}$-sulfonyl aldimines}

The aza-Diels-Alder reaction of electron-rich dienes with aldimines is an extremely powerful strategy for the construction of six-membered nitrogen heterocycles [10]. In spite of its great synthetic potential in medicinal chemistry and alkaloid synthesis, very few efficient asymmetric catalytic versions of azaDiels-Alder reaction have been developed to date [11]. To test the usefulness of Fesulphos ligands in this process, we selected the reaction of Danishefsky diene with the $N$-tosylimine of benzaldehyde as a model reaction. In this transformation, the $\mathrm{Cu}$ complexes afforded the best results in terms of both reactivity and enantioselectivity.

The dimeric complexes $[(\mathbf{3}) \cdot \mathrm{CuX}]_{2}(\mathrm{X}=\mathrm{Cl}$ or $\mathrm{Br})$ were readily prepared by reaction of ligand $\mathbf{3}$ with $\mathrm{CuX}$ in THF-MeOH (rt, $5 \mathrm{~min}$ ), and easily isolated as air-stable orange solids by simple addition of a 4:1 mixture of hexane-EtOAc and filtration through a short pad of silica gel. Their tetrahedral-like structure around $\mathrm{Cu}$ was determined by X-ray diffraction of $[(\mathbf{3 a}) \cdot \mathrm{CuCl}]_{2}$. A catalytic amount of these dimeric complexes $\left(5.1 \mathrm{~mol} \%\right.$ ), in combination with a silver salt (usually $\mathrm{AgClO}_{4}, 10 \mathrm{~mol} \%$ ), led predominantly to the Mannich-type addition product $\mathbf{6}$, which was readily transformed into the cycloadduct 7 upon addition of TFA to the reaction mixture. As shown in Scheme 9, the enantioselectivity of the process proved to be highly dependent of the substitution at phosphorus, being the bulky complex $[\mathbf{3 f} \cdot \mathrm{CuBr}]_{2}$ the most efficient $\left(93 \%\right.$ ee at $\mathrm{rt}$, and $97 \%$ ee at $\left.-20{ }^{\circ} \mathrm{C}\right)$.

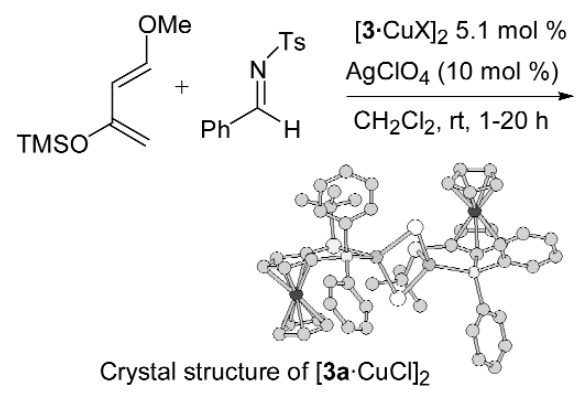

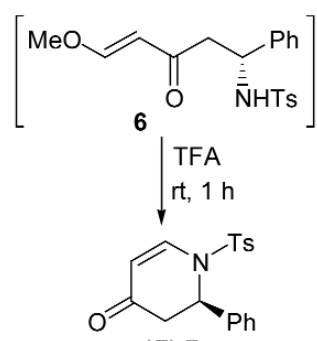

$(R)-7$

\begin{tabular}{lll}
\hline \multirow{2}{*}{ Complex } & \multicolumn{2}{c}{$(R)-\mathbf{7}$} \\
\cline { 2 - 3 } & yield $(\%)$ & ee $(\%)$ \\
\hline$[\mathbf{3 a} \cdot \mathrm{CuCl}]_{2}$ & 79 & 80 \\
{$[\mathbf{3 b} \cdot \mathrm{CuCl}]_{2}$} & 70 & 71 \\
{$[3 \mathbf{c} \cdot \mathrm{CuCl}]_{2}$} & 57 & 60 \\
{$[\mathbf{3 d} \cdot \mathrm{CuCl}]_{2}$} & 58 & 71 \\
{$[\mathbf{3 e} \cdot \mathrm{CuCl}]_{2}$} & 66 & 57 \\
{$[\mathbf{3 f} \cdot \mathrm{CuCl}]_{2}$} & 96 & 80 \\
{$[3 \mathbf{3 f} \cdot \mathrm{CuBr}]_{2}$} & 90 & $93(97)^{\mathrm{a}}$ \\
${ }^{\mathrm{a}}$ Reaction performed at $-20^{\circ} \mathrm{C}$
\end{tabular}

Scheme 9 Fesulphos- $\mathrm{Cu}(\mathrm{I})$ complexes as catalysts in the reaction of Danishefsky diene with $N$-tosylimine of benzaldehyde.

With optimized complex $[\mathbf{3 f} \cdot \mathrm{CuBr}]_{2}$ in hand, the scope of the reaction was next explored with a variety of $N$-sulfonyl imines. Interestingly, good yields (usually in the range 60-90\%) and outstanding high asymmetric inductions (75-98\% ee) were obtained with a wide variety of substrates, including imines of aromatic, alkenyl, and even aliphatic aldehydes, as well as alkyl-substituted Danishefsky dienes. This catalyst system also tolerates different aromatic substitution at the $N$-sulfonyl group, which offers varied possibilities for the deprotection of the final cycloadducts. Figure 2 shows some of the enantioenriched dihydropyridones prepared by this methodology. Finally, it is important to note that these $N$-sulfonyl dihydropyridones are crystalline solids, giving rise to enantiopure samples $(>99.5 \%$ ee) upon a single recrystallization. To illustrate the interest of these heterocycles in alkaloid synthesis, 
we have developed a very short stereodivergent synthesis of (+)-Lasubine I and II from the enantiopure dihydropyridone $\mathbf{8}$ as key starting material (Scheme 10).<smiles>Cc1ccc(S(=O)(=O)N2C=CC(=O)C[C@H]2c2ccccc2)cc1</smiles>

$84 \%, 97 \%$ ee $\left(-20^{\circ} \mathrm{C}\right)$<smiles>COc1ccc(S(=O)(=O)N2C=CC(=O)C[C@H]2c2ccccc2)cc1</smiles>

$61 \%, 94 \%$ ee $(\mathrm{rt})$<smiles>O=C1C=CN(S(=O)(=O)c2ccc([N+](=O)[O-])cc2)[C@H](c2ccccc2)C1</smiles>

$58 \%, 90 \%$ ee (rt)<smiles>O=C1C=CN(S(=O)(=O)c2cccs2)[C@H](c2ccccc2)C1</smiles>

$50 \%, 93 \%$ ee $(\mathrm{rt})$<smiles>O=C1C=CN([AsH3])[C@H](c2ccc(F)cc2)C1</smiles>

$50 \%, 93 \%$ ee $\left(-20^{\circ} \mathrm{C}\right)$<smiles>CCC[C@@H]1CC(=O)C=CN1[Hg]</smiles>

$87 \%, 82 \%$ ee $\left(-20^{\circ} \mathrm{C}\right)$<smiles>COc1ccc([C@H]2CC(=O)C=CN2[AsH3])cc1</smiles>

$76 \%, 91 \%$ ee

(rt)<smiles>O=C1C=CN([AsH3])C(c2ccc3ccccc3c2)C1</smiles>

$58 \%, 93 \%$ ee $\left(-20^{\circ} \mathrm{C}\right)$<smiles>O=C1C=CN([AlH2])C(/C=C/c2ccccc2)C1</smiles>

$82 \%, 96 \%$ ee $\left(-20^{\circ} \mathrm{C}\right)$<smiles>C/C=C/C1CC(=O)C=CN1[AlH2]</smiles>

$84 \%, 97 \%$ ee $\left(-20^{\circ} \mathrm{C}\right)$

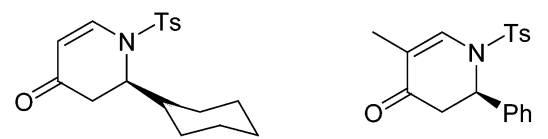

$82 \%, 96 \%$ ee $\left(-40^{\circ} \mathrm{C}\right)$
$70 \%, 92 \%$ ee $\left(0^{\circ} \mathrm{C}\right)$<smiles>CC1=CN([TeH])C(/C=C/P)CC1=O</smiles>

$57 \%, 88 \%$ ee $\left(-20^{\circ} \mathrm{C}\right)$<smiles>CC1=CN([13F])C(c2ccccc2)[C@H](C)C1=O</smiles>

$53 \%, 75 \%$ ee $\left(-78^{\circ} \mathrm{C}\right)$

Fig. 2 Scope of the enantioselective synthesis of $N$-sulfonyl dihydropyridones using $[3 \mathbf{f f} \cdot \mathrm{CuBr}]_{2} / \mathrm{AgClO}_{4}$ as catalyst system.

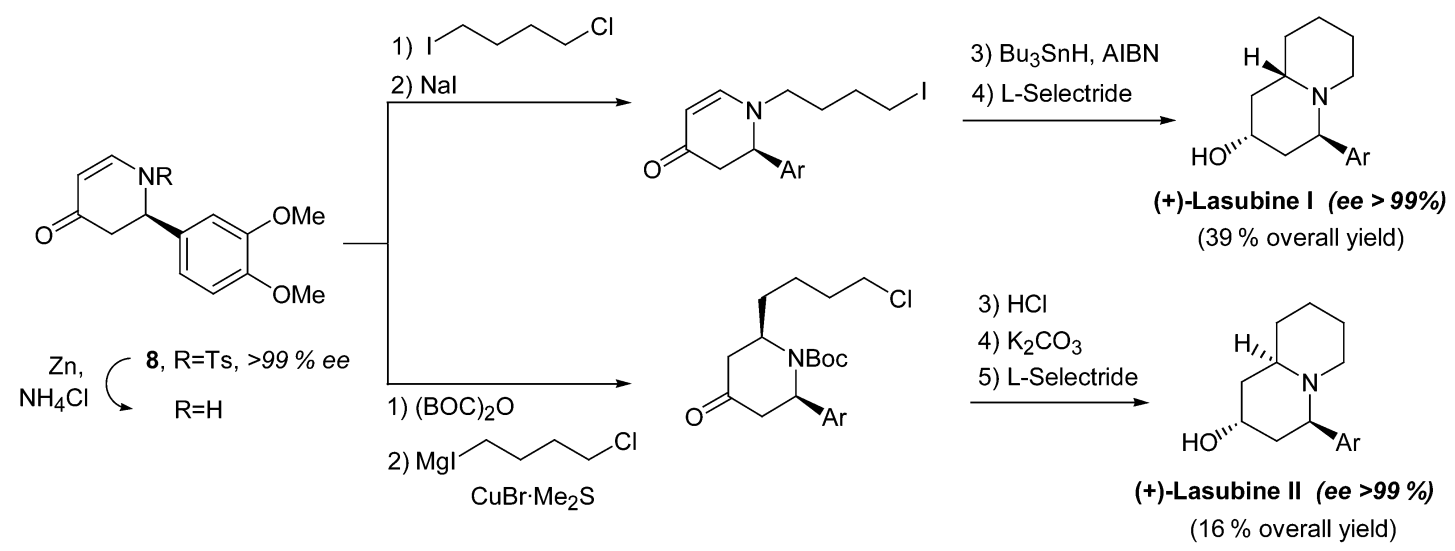

Scheme 10 Application to the stereodivergent synthesis of (+)-Lasubine I and II.

\section{CONCLUSION}

Transition-metal complexes of the readily available and tunable family of planar chiral P,S-ligands 1-tert-butylsulfenyl-2-phosphinoferrocenes (Fesulphos) behave as efficient catalysts in a variety of enantioselective reactions, including Pd-catalyzed allylic substitutions, Pd-catalyzed alkylative ring opening of oxa- and azabicyclic [2.2.1]-alkenes with dialkylzinc reagents and [4+2] cycloaddition processes. Very high enantioselectivities have been reached in all these reactions by easy fine-tuning of the steric and electronic properties at phosphorus, highlighting the potentially broad scope of Fesulphos ligands in asymmetric catalysis. 


\section{ACKNOWLEDGMENTS}

Financial support by the Ministerio de Educación y Ciencia (MEC, BQU2003-0508) and Consejería de Educación de la Comunidad de Madrid (GR/MAT/0016/2004) is gratefully acknowledged. R.G.A. thanks the MEC for a Ramon y Cajal contract. O.G.M. and P.M. thank MEC for their predoctoral fellowships. S.C. thanks the Universidad Autónoma de Madrid for a predoctoral fellowship.

\section{REFERENCES AND NOTES}

1. (a) Catalytic Asymmetric Synthesis, $2^{\text {nd }}$ ed., I. Ojima (Ed.), Wiley-VCH, New York (2000); (b) Comprehensive Asymmetric Catalysis, E. N. Jacobsen, A. Pfaltz, H. Yamamoto (Eds.), Springer, Berlin (1999).

2. A. Pfatz and W. J. Drury III. Proc. Natl. Acad. Sci. USA 101, 5723-5726 (2004).

3. (a) O. García Mancheño, J. Priego, S. Cabrera, R. Gómez Arrayás, T. Llamas, J. C. Carretero. J. Org. Chem. 68, 3679-3686 (2003); (b) R. Gómez Arrayás, O. García Mancheño, J. C. Carretero. Chem. Commun. 1654-1655 (2004).

4. (a) J. Priego, O. García Mancheño, S. Cabrera, R. Gómez Arrayás, T. Llamas, J. C. Carretero. Chem. Commun. 2512-2513 (2002); (b) S. Cabrera, R. Gómez Arrayás, J. C. Carretero. J. Am. Chem. Soc. 127, 17938-17947 (2005).

5. O. García Mancheño, R. Gómez Arrayás, J. C. Carretero. Organometallics 24, 557-561 (2005).

6. O. García Mancheño, R. Gómez Arrayás, J. C. Carretero. J. Am. Chem. Soc. 126, 456-457 (2004).

7. F. Rebière, O. Riant, L. Ricard, H. B. Kagan. Angew. Chem., Int. Ed. Engl. 32, 568-570 (1993).

8. (a) M. Lautens, J.-L. Renaud, S. Hiebert. J. Am. Chem. Soc. 122, 1804-1805 (2000); (b) for a review, see: M. Lautens, K. Fagnou, S. Hiebert. Acc. Chem. Res. 36, 48-58 (2003).

9. M. Lautens and S. Hiebert. J. Am. Chem. Soc. 126, 1437-1447 (2004).

10. (a) J. P. Michael. In The Alkaloids, Vol. 55, G. A. Cordell (Ed.), Academic Press, San Diego (2001); (b) for the potential of enantiopure 2,3-dihydro-4-pyridones in alkaloid synthesis, see: D. L. Comins, S. Huang, C. L. McArdle, C. L. Ingalls. Org. Lett. 3, 469-471 (2001).

11. For previous catalytic asymmetric aza-Diels-Alder reactions, see: (a) S. Yao, S. Saaby, R. G. Hazell, K. A. Jørgensen. Chem. Eur. J. 6, 2435-2448 (2000); (b) N. S. Josephsohn, M. L. Snapper, A. H. Hoveyda. J. Am. Chem. Soc. 125, $4018-4019$ (2003); (c) S. Kobayashi, M. Ueno, S. Saito, Y. Mizuki, H. Ishitani, Y. Yamashita. Proc. Natl. Acad. Sci. USA 101, 5476-5481 (2004), and references cited therein; (d) S. Guillarme and A. Whiting. Synlett 711-713 (2004); (d) Y. Yamashita, Y. Mizuki, S. Kobayashi. Tetrahedron Lett. 46, 1803-1806 (2005). 